\title{
A COPULA-BASED METHOD FOR RELIABILITY SENSITIVITY ANALYSIS OF STRUCTURAL SYSTEM WITH CORRELATED FAILURE MODES
}

\author{
OPARTA NA POJĘCIU KOPUŁY METODA ANALIZY CZUŁOŚCI \\ NIEZAWODNOŚCIOWEJ SYSTEMU KONSTRUKCYJNEGO \\ O SKORELOWANYCH PRZYCZYNACH USZKODZEŃ
}

\begin{abstract}
Despite many advances in the field of computational reliability analysis, the efficient estimation of the reliability and reliability sensitivity analysis of structural systems with multiple failure modes remains a persistent challenge. The key to deal with the problem lies in the correlation modelling between failure modes. In this paper, the Archimedean copulas are used as an alternative to solve the high-dimensional dependence modeling problem. The probability characteristics of failure modes are described by stochastic perturbation technique, and the reliability index is estimated with the fourth-moment standardization method. Considering that the number of the potential failure modes of the structural systems are relatively large, the probabilistic network evaluation technique is adopted to reduce the computational complexity. The sensitivity analysis is then conducted using the matrix differential technology. The numerical examples show that the applied procedure is able to efficiently consider various failure modes of structural systems in probabilistic assessment and sensitivity analysis.
\end{abstract}

Keywords: reliability; reliability sensitivity; correlation analysis; copula.

\begin{abstract}
Mimo poważnych osiagnięć $w$ dziedzinie komputerowej analizy niezawodności, skutecznaocena niezawodności i analiza czułości niezawodnościowej systemów konstrukcyjnych o wielu przyczynach uszkodzeń pozostaja ciagłym wyzwaniem. Kluczem do rozwiąania problemu jest modelowanie korelacji między przyczynami uszkodzeń. W niniejszym artykule zastosowano kopuly Archimedesa jako alternatywny sposób rozwiazania problemu modelowania zależności wysoko wymiarowych. Charakterystyki prawdopodobieństwa dla przyczyn uszkodzeń opisano przy pomocy metody zaburzeń stochastycznych, zaś wskaźnik niezawodności oszacowano metoda standaryzacji momentu czwartego rzędu. Biorąc pod uwagę, że liczba potencjalnych przyczyn uszkodzeń systemów konstrukcyjnych jest stosunkowo duża, wykorzystano technikę oceny z zastosowaniem sieci probabilistycznych, która pozwala na zmniejszenie złożoności obliczeniowej. Następnie przeprowadzono analizę czułości przy użyciu metody macierzy równań różniczkowych. Przyktady liczbowe pokazuja, że zastosowana procedura pozwala na skuteczna ocenę różnych przyczyn uszkodzeń systemów konstrukcyjnych w ramach oceny probabilistycznej oraz analizy czułości.
\end{abstract}

Stowa kluczowe: niezawodność; czułość niezawodnościowa; analiza korelacji; kopuła.

\section{Introduction}

Generally, structural system is composed of multiple components, the state of the structural system (failure or safe) depends on that of each component. The reliability of the structural system is then determined by the component reliability. Comparing with the reliability analysis of single structure element, the system reliability analysis becomes more difficult especially when the failure of the components is correlated.

The reliability analysis methods for structural system, such as Monte Carlo simulation method, bound method, and surrogate model method, has provided as efficient approaches for system reliability analysis. However, the methods have their own limitations. The Monte Carlo simulation method demanded enormous computational cost for assessing the low probability events [16]. The bound method have been widely used for computing reliability interval on the probabilities of series and parallel system, but cannot give a determined value $[5,19]$. The first-order system reliability method transforms system reliability problems into multi-normal calculations based on the results of component reliability $[8,10]$, which is applicable to series and parallel system reliability problems. The surrogate model method is very useful and effective dealing with implicit limit state function problems [1]. Zhao proposed a moment-based method for structural system reliability assessment which is applicable to both series and non-series systems [23]. Kang proposed a matrix-based system reliability (MSR) method to estimate the probabilities of complex system events by simple matrix calculations [9].

The existing system reliability methods are not flexible in incorporating various types and amount of available information on components and their statistical dependence. The Pearson correlation coefficient is frequently used to describe the linear correlation between failure modes, whereas the correlation of failure modes in structural systems are generally nonlinear. As a tool to establish a joint distribution function from its marginal distributions, copula functions are often adopted to solve the correlation problems [6,21]. Copula functions are useful tools for modeling dependence among the components. They provide a way of specifying joint distributions if only the marginal distributions are known. In terms of system reliability of multiple failure modes, the multivariate distribution could be built using the marginal distributions of each failure mode and the copula function.

Reliability-based sensitivity refers to the partial derivative of the reliability with respect to basic random variables $[13,24]$. It ranks the design variables and guides the reliability design [25]. Reliability sen- 
sitivity analysis has been used to obtain the change rate of a structure response due to the random inputs $[11,12]$. In terms of system reliability sensitivity problem, the independent assumption of multiple failure modes may lead to incorrect result. Thus, it is important to develop an efficient method for the reliability-based sensitivity estimation with dependent failure modes.

A novel method is proposed here to deal with the system reliability and reliability-based sensitivity problem of the structural systems. The stochastic perturbation technique is adopted to obtain the first few moments of the limit state function of failure mode. The fourthmoment standardization method is then used to calculate the reliability of each failure mode. The correlation between failure modes are estimated with the copula-based cumulated distribution function. The reliability-based sensitivity with respect to the random variables is then obtained by the matrix differential technology.

Section 2 provides an introduction to copulas. Section 3 firstly describes the reliability modeling procedure of the component reliability and then develops the method into the system level. Section 4 proposes the reliability-based sensitivity modeling procedure based on the system reliability model. Section 5 applies the newly derived method to the structural system problems, comparing its accuracy to sampling methods. Section 6 provides some conclusions on the proposed method.

\section{Copulas}

The copula of a multivariate distribution describes not only the correlations of the random variables, but also the dependence structure. It is uncoupled from the marginal distributions which can be modeled as empirical distributions or fitted standard distributions as usual [17]. After modeling the marginal distributions, then the estimation of the corresponding copula function could be carried out. A compact definition of copula function is given in [21]. The use of copula is common in finance and insurance. In this paper, we propose to use copula for the analysis of correlated failure modes in structural systems.

According to the Sklar theory [20], let $F_{i}\left(g_{i}(X)\right)$ and $F_{j}\left(g_{j}(X)\right)$ denote the marginal distribution functions of the failure modes $g_{i}(\boldsymbol{X})$ and $g_{j}(\boldsymbol{X})$, respectively. The joint distribution function $F_{i j}\left(g_{i}, g_{j}\right)$ can be expressed as:

$$
F_{i j}\left(g_{i}, g_{j}\right)=C\left[F_{i}\left(g_{i}(x)\right), F_{j}\left(g_{j}(x)\right)\right]
$$

where $C(u, v)$ is the copula function.

In the case of $n$ marginal distribution functions, the joint distribution function of $n$ failure modes could be similarly modeled as:

$$
F\left(g_{i}, g_{j}, \cdots, g_{n}\right)=C\left[F_{i}\left(g_{i}(x)\right), F_{j}\left(g_{j}(x)\right), \cdots, F_{n}\left(g_{n}(x)\right)\right]
$$

The Sklar theory provides an efficient way to model the dependence structure of random variables with the copula functions. However, the using of high-dimensional copula function makes it inevitably encounter the problem of parameter estimation, which is generally difficult to obtain. To overcome this problem, the Archimedean copulas are used as an alternative to solve the high-dimensional dependence modeling problem. The family of Archimedean copulas has been studied extensively by a number of authors including [2, 4, 7, 22]. Well known representatives of the Archimedean family are GumbelHougaard, Frank and Clayton copula. The generator and parameter range of these Archimedean copulas are shown in Table 1, for more details, the reader is referred to [17]. Due to the characteristics of the Archimedean copula functions, any $N$-dimension Archimedes copula function could be deduced from a bivariant one [18]. Thus, the reliability problem with multiple failure modes could be transformed into the bivariant form:

$$
\begin{aligned}
& C\left(u_{1}, u_{2}, u_{3}\right)=C\left(C\left(u_{1}, u_{2}\right), u_{3}\right) \\
& C\left(u_{1}, u_{2}, u_{3}, u_{4}\right)=C\left(C\left(u_{1}, u_{2}, u_{3}\right), u_{4}\right) \\
& C\left(u_{1}, u_{2}, \cdots, u_{N-1}, u_{N}\right)=C\left(C\left(u_{1}, u_{2}, \cdots, u_{N-1}\right), u_{N}\right)
\end{aligned}
$$

Thus, the first derivation of the copula-based CDF with respecet to the random parameter $\zeta$ (i.e. the mean, variance, et al.) can be obtained straightforwardly,

$$
\begin{aligned}
\frac{\partial C\left(P_{1}, P_{2}, \cdots, P_{m}\right)}{\partial \zeta}= & \frac{\partial C\left(P_{1}, P_{2}, \cdots, P_{m}\right)}{\partial C\left(P_{1}, P_{2}, \cdots, P_{m-1}\right)}\left(\frac{\partial C\left(C\left(P_{1}, P_{2}, P_{m-2}\right), P_{m-1}\right)}{\partial C\left(P_{1}, P_{2}, P_{m-2}\right)} \cdots\right. \\
& \left(\frac{\partial C\left(C\left(P_{1}, P_{2}\right), P_{3}\right)}{\partial C\left(P_{1}, P_{2}\right)}\left(\frac{\partial C\left(P_{1}, P_{2}\right)}{\partial P_{1}} \frac{\partial P_{1}}{\partial \zeta}+\frac{\partial C\left(P_{1}, P_{2}\right)}{\partial P_{2}} \frac{\partial P_{2}}{\partial \zeta}\right)+\right. \\
& \left.\left.\frac{\partial C\left(C\left(P_{1}, P_{2}\right), P_{3}\right)}{\partial P_{3}} \frac{\partial P_{3}}{\partial \zeta}\right)+\cdots+\frac{\partial C\left(C\left(P_{1}, P_{2}, P_{3}\right), P_{m-1}\right)}{\partial P_{m-1}} \frac{\partial P_{m-1}}{\partial \zeta}\right)+ \\
& \frac{\partial C\left(C\left(P_{1}, P_{2}, \cdots, P_{m-1}\right), P_{m}\right)}{\partial P_{m}} \frac{\partial P_{m}}{\partial \zeta}
\end{aligned}
$$

Table 1. The generator and parameter range of commonly used Archimedean copula functions

\begin{tabular}{llc}
\hline Archimedean Copula & \multicolumn{1}{c}{ Generator } & \multicolumn{1}{c}{ Parameter range } \\
Clayton & $\varphi_{\theta}(x)=(1+\theta x)_{+}^{-1 / \theta}$ & $\theta \neq 0, \alpha_{+}=\max \{\alpha, 0\}$ \\
Gumbel-Hougaard & $\varphi_{\theta}(x)=\exp \left(-x^{1 / \theta}\right)$ & $\theta \geq 1$ \\
Frank copula & $\varphi_{\theta}(x)=-\frac{1}{\theta} \ln \left(\frac{\exp (x)+\exp (-\theta)-1}{\exp (x)}\right)$ & $\theta \neq 0$ \\
Ali-Mikhail-Haq & $\varphi_{\theta}(x)=\frac{1-\theta}{\exp (x)-\theta}$ & $\theta \in[-1,1]$
\end{tabular}

In this paper, authors applied a useful application of the GumbelHougaard copula in the reliability analysis of structural systems . The distribution function of the Gumbel-Hougaard copula is as follows:

$$
C_{G}(u, v ; \theta)=\exp \left(-\left[(-\ln u)^{\frac{1}{\theta}}+(-\ln v)^{\frac{1}{\theta}}\right]^{\theta}\right) \theta \in(0,1]
$$

The expression of the first derivative of the Gumbel-Hougaard copula with respect to variable ( $u$ and $v$ ) could be obtained as:

$$
\frac{\partial C_{G}(\mu, v)}{\partial u}=-\frac{\left((-\ln (u))^{\frac{1}{\theta}}+(-\ln (v))^{\frac{1}{\theta}}\right)^{\theta}(-\ln (u))^{\frac{1}{\theta}} \mathrm{e}^{-\left((-\ln (u))^{\frac{1}{\theta}}+(-\ln (v))^{\frac{1}{\theta}}\right)^{\theta}}}{u \ln (u)\left((-\ln (u))^{\frac{1}{\theta}}+(-\ln (v))^{\frac{1}{\theta}}\right)}
$$




$$
\frac{\partial C_{G}(\mu, v)}{\partial v}=-\frac{\left((-\ln (u))^{\frac{1}{\theta}}+(-\ln (v))^{\frac{1}{\theta}}\right)^{\theta}(-\ln (v))^{\frac{1}{\theta}} \mathrm{e}^{-\left((-\ln (u))^{\frac{1}{\theta}}+(-\ln (v))^{\frac{1}{\theta}}\right)^{\theta}}}{v \ln (v)\left((-\ln (u))^{\frac{1}{\theta}}+(-\ln (v))^{\frac{1}{\theta}}\right)}
$$

\section{Reliability estimation of structural systems}

Structural systems normally have a variety of potential failure modes, which results in that the probabilistic analysis of the structural system is thus becomes a system reliability problem. Moreover, the correlation between failure modes can have a profound effect on their practical reliability and the neglect of such correlation may lead to excessive errors or even wrong conclusion.

Each failure mode caused by the failure of a group of structure components could be seemed as a parallel system, and the system failure could then be considered as a series failure of these failure modes. Consequently, the system reliability estimation of the structural system is to calculate the reliability of the series-parallel system. Generally, a parallel system formed from a failure path is seemed as a failure mode and the corresponding limit state function can be obtained in mechanics. A structural system could therefore be simplified into a series system of multiple failure modes.

The reliability problem of structural systems with multiple failure modes can be expressed as:

$$
\begin{gathered}
R=P(G>0)=\int_{0}^{\infty} f_{G}(G) \mathrm{d} G \\
G(\boldsymbol{X})=\left(g_{1}(\boldsymbol{X}), g_{2}(\boldsymbol{X}), \cdots, g_{n}(\boldsymbol{X})\right)^{\mathrm{T}}
\end{gathered}
$$

where $\boldsymbol{X}=\left\{X_{i}\right\}_{i=1}^{n}$ denotes the random variable vector and $G(X)$ defines the limit state functions of multiple failure modes.

The first four moment of the random variable $\boldsymbol{X}$ can be deduced as follows according to the perturbation theory:

$$
\begin{gathered}
\mathrm{E}(\boldsymbol{X})=\overline{\boldsymbol{X}}=\mathrm{E}\left(\boldsymbol{X}_{\mathrm{d}}\right)+\varepsilon \mathrm{E}\left(\boldsymbol{X}_{\mathrm{p}}\right)=\boldsymbol{X}_{\mathrm{d}} \\
\operatorname{Var}(\boldsymbol{X})=\mathrm{E}\left\{[\boldsymbol{X}-\mathrm{E}(\boldsymbol{X})]^{[2]}\right\}=\varepsilon^{2}\left[\boldsymbol{X}_{\mathrm{p}}^{[2]}\right] \\
\mu_{3}(\boldsymbol{X})=\mathrm{E}\left\{[\boldsymbol{X}-\mathrm{E}(\boldsymbol{X})]^{[3]}\right\}=\varepsilon^{3}\left[\boldsymbol{X}_{\mathrm{p}}^{[3]}\right] \\
\boldsymbol{\mu}_{4}(\boldsymbol{X})=\mathrm{E}\left\{[\boldsymbol{X}-\mathrm{E}(\boldsymbol{X})]^{[4]}\right\}=\varepsilon^{4}\left[\boldsymbol{X}_{\mathrm{p}}^{[4]}\right]
\end{gathered}
$$

where $(\bullet)^{[k]}$ represents the Kronecker product, i.e.,

$$
(\bullet)^{[k]}=(\bullet) \otimes(\bullet) \otimes \cdots \otimes(\bullet),(A)_{p \times q} \otimes(B)_{s \times t}=\left[a_{i j} B\right]_{p s \times q t} \text {. }
$$

Due to that the complete statistical information of random variables cannot be fully accessed in most practical cases, the statistical moments higher than the fourth order are difficult to obtain. Thus, the moments of each failure mode are considered here according to the engineering reality, the corresponding expression in matrix form could be obtained according to the perturbation theory

$$
\begin{gathered}
\operatorname{Var}[g(\boldsymbol{X})]=\left(\frac{\partial g_{\mathrm{d}}(\boldsymbol{X})}{\partial \boldsymbol{X}^{T}}\right)^{[2]} \operatorname{Var}(\boldsymbol{X}) \\
\theta_{g i}=\left(\frac{\partial g_{\mathrm{d}}(\boldsymbol{X})}{\partial \boldsymbol{X}^{T}}\right)^{[3]} \mu_{3}(\boldsymbol{X}) \\
\eta_{g i}=\left(\frac{\partial g_{\mathrm{d}}(\boldsymbol{X})}{\partial \boldsymbol{X}^{T}}\right)^{[4]} \mu_{4}(\boldsymbol{X})
\end{gathered}
$$

According to the reliability theory, for a given limit state function $z_{i}=g_{i}(\boldsymbol{X})$, the reliability index and reliability could be defined as:

$$
\beta_{S i}=\frac{\mathrm{E}\left[g_{i}(\boldsymbol{X})\right]}{\sqrt{\operatorname{Var}\left[g_{i}(\boldsymbol{X})\right]}}
$$

Equation (17) use only the first two moments, i.e. the mean and the variance of the limit state function, which is suitable for the case that the basic random variables are normally distributed. As a matter of fact, the distribution types of the random variables are unknown on most occasions, the complete probabilistic information needed is unable to obtain. To overcome this problem, the fourth-moment reliability index is adopted here [23], and the reliability index of each failure mode could be expressed as the following equation according to the theory,

$$
\beta_{F i}=\frac{3\left(\alpha_{4 g i}-1\right) \beta_{S i}+\alpha_{3 g i}\left(\beta_{S i}^{2}-1\right)}{\sqrt{\left(9 \alpha_{4 g i}-5 \alpha_{3 g i}^{2}-9\right)\left(\alpha_{4 g i}-1\right)}}
$$

where $\quad \alpha_{3 g i}=\theta_{g i} / \sigma_{g i}^{3}, \quad \alpha_{4 g i}=\eta_{g i} / \sigma_{g i}^{4}$ represent the coefficients of skewness and kurtosis of the $i$ th failure mode, respectively. $\theta_{g i}$ and $\eta_{g i}$ are the third and the fourth central moment of the $i$ th failure mode.

Each failure mode can be represented as a limit state function $g_{i}(\boldsymbol{X})$, and the system reliability could then be expressed as:

$$
\begin{aligned}
R & =P\left\{g_{1}(\boldsymbol{X})>0 \cap g_{2}(\boldsymbol{X})>0 \cap \cdots g_{n}(\boldsymbol{X})>0\right\} \\
& =\int_{0}^{\infty} \cdots \int_{0}^{\infty} f_{G}\left(g_{1}, g_{2}, \cdots g_{n}\right) \mathrm{d} g_{1} g_{1} \cdots \mathrm{d} g_{n}
\end{aligned}
$$

where $f_{G}\left(g_{1}, g_{2}, \cdots g_{n}\right)$ is the joint probability density function of the potential failure modes.

Comparing to mechanical components, the failure of a structural system is usually accompanied with much more failure modes, which results in that the reliability analysis becomes much more complex. In order to overcome this problem, the probabilistic network evaluation technique (PNET) is adopted in this paper to identify the representative failure modes in structural system and reduce the complexity of the analysis procedure [15]. According to the PNET, failure modes of 
which the correlation coefficient $\square \rho_{i j} \square>\rho_{0}$ are considered as highly correlated modes, and the one with a less reliability index is selected as the representative failure mode. By repeating the procedure, all the representative failure modes can be selected. By using PNET, the system reliability problem of the structural system is simplified and only the representative failure modes is taken into account. In this case, according to the probabilistic theory and the copula-based cumulative distribution functions, the failure probability of the structural system with respect to $m$ representative failure modes could then be expressed as:

$$
\begin{aligned}
P=P( & \left.\bigcup_{j=1}^{m} g_{j}\left(X_{1}, X_{2}, \cdots, X_{n}\right) \leq 0\right)=\sum_{j=1}^{m} P_{j}-\sum_{1 \leq k<l \leq m} C\left(P_{k}, P_{l}\right)+ \\
& \sum_{1 \leq k<l<s \leq m} C\left(C\left(P_{k}, P_{l}\right), P_{s}\right)-\cdots+(-1)^{m-1} C\left(C\left(P_{1}, P_{2}, \cdots, P_{m-1}\right), P_{m}\right)
\end{aligned}
$$

where $P_{j}$ denotes the failure probability of the $j$ th representative failure mode.

\section{Copula-based reliability sensitivity analysis}

Based on the scheme of the reliability analysis of structural system, the structural sensitivity analysis could then be performed. Reliability-based sensitivity involves studying the dependence of the failure probability on design parameters and refers to the partial derivative of the reliability with respect to design parameters $\zeta$, such as the mean and the variance $[14,24]$.

Based on the matrix differential technology and copula-based joint probability distribution function, the reliability-based sensitivity with respect to random parameters of random variables (the mean $\zeta_{1}$ and the variance $\zeta_{2}$ ) considering correlated failure modes could be expressed as follows:

$$
\frac{\partial P}{\partial \zeta}=\sum_{j=1}^{m} \frac{\partial P_{j}}{\partial \zeta}-\sum_{1 \leq k \leq l \leq m} \frac{\partial C\left(P_{k}, P_{l}\right)}{\partial \zeta}+\sum_{1 \leq k \leq 1 \leq s \leq m} \frac{\partial C\left(P_{k}, P_{l}, P_{s}\right)}{\partial \zeta}-\cdots+(-1)^{m-1} \frac{\partial C\left(P_{1}, P_{2}, \cdots P_{m}\right)}{\partial \zeta}
$$

where:

$$
\begin{gathered}
\frac{\partial P_{j}}{\partial \zeta_{1}}=\frac{\partial P_{j}\left(\beta_{\mathrm{Fi}}\right)}{\partial \beta_{F i}}\left\{\frac{\partial \beta_{\mathrm{Fi}}}{\partial \beta_{S i}}\left[\frac{\partial \beta_{S i}}{\partial \mu_{g i}} \frac{\partial \mu_{g i}}{\partial \zeta_{1}}+\frac{\partial \beta_{S i}}{\partial \sigma_{g i}} \frac{\partial \sigma_{g i}}{\partial \zeta_{1}}\right]+\frac{\partial \beta_{F i}}{\partial \sigma_{g i}} \frac{\partial \sigma_{g i}}{\partial \zeta_{1}}\right\} \\
\frac{\partial P_{j}\left(\beta_{F i}\right)}{\partial \beta_{F i}}=-\varphi\left(-\beta_{F i}\right) \\
\frac{\partial \beta_{F i}}{\partial \beta_{S i}}=\frac{3\left(\alpha_{4 g i}-1\right)+2 \alpha_{3 g i} \beta_{S i}}{\sqrt{\left(5 \alpha_{3 g i}^{2}-9 \alpha_{4 g i}+9\right)\left(1-\alpha_{4 g i}\right)}} \\
\frac{\partial \beta_{S i}}{\partial \mu_{g i}}=\frac{1}{\sigma_{g i}} \\
\frac{\partial \mu_{g i}}{\partial \zeta_{1}}=\left[\frac{\partial g_{i}}{\partial \zeta_{11}}, \cdots, \frac{\partial g_{i}}{\partial \zeta_{1 n}}\right] \\
\frac{\partial \beta_{S i}}{\partial \sigma_{g i}}=-\frac{\mu_{g i}}{\sigma_{g i}^{2}}
\end{gathered}
$$

$$
\begin{gathered}
\frac{\partial \beta_{F i}}{\partial \sigma_{g i}}=\frac{\left(\alpha_{3 g i}\left(3-5 \beta_{S i}^{2}\right)-15 \alpha_{4 g i} \beta_{S i}+3 \beta_{S i}\right) / \sigma_{g i}}{\sqrt{\left(9 \alpha_{4 g i}-5 \alpha_{3 g i}^{2}-9\right)\left(\alpha_{4 g i}-1\right)}} \\
-\frac{1}{2} \frac{\left[3 \beta_{\mathrm{Si}}\left(\alpha_{4 g i}-1\right)+\alpha_{3 g i}\left(\beta_{S i}^{2}-1\right)\right]}{\sqrt{\left(9 \alpha_{4 g i}-5 \alpha_{3 g i}^{2}-9\right)^{3}\left(\alpha_{4 g i}-1\right)^{3}}}\left(50 \alpha_{3 g i}^{2} \alpha_{4 g i}-30 \alpha_{3 g i}^{2}-72 \alpha_{4 g i}^{2}+72 \alpha_{4 g i}\right) / \sigma_{g i}
\end{gathered}
$$$$
\frac{\partial \sigma_{g i}}{\partial \zeta_{1}}=\frac{1}{2 \sigma_{g i}}\left[\frac{\partial^{2} g_{i}}{\partial \zeta_{1}^{2}} \otimes \frac{\partial g_{i}}{\partial \zeta_{1}}+\left(\frac{\partial^{2} g_{i}}{\partial \zeta_{1}{ }^{2}} \otimes \frac{\partial g_{i}}{\partial \zeta_{1}}\right)\left(\boldsymbol{I}_{n} \otimes \boldsymbol{U}_{n^{2} \times n^{2}}\right)\right]\left(\boldsymbol{I}_{n} \otimes \operatorname{Var}(\boldsymbol{X})\right)
$$

$$
\frac{\partial P_{i}}{\partial \zeta_{2}}=\frac{\partial P_{i}\left(\beta_{F i}\right)}{\partial \beta_{F i}}\left(\frac{\partial \beta_{F i}}{\partial \beta_{S i}} \frac{\partial \beta_{S i}}{\partial \sigma_{g i}}+\frac{\partial \beta_{F i}}{\partial \sigma_{g i}}\right) \frac{\partial \sigma_{g i}}{\partial \zeta_{2}}
$$

$$
\frac{\partial \sigma_{g i}}{\partial \zeta_{2}}=\frac{1}{2 \sigma_{g i}}\left[\frac{\partial \bar{g}_{i}}{\partial \boldsymbol{X}} \otimes \frac{\partial \bar{g}_{i}}{\partial \boldsymbol{X}}\right]
$$

According to the known probabilistic information of the random variables, the reliability sensitivity of the structure system with $m$ correlated representative failure modes could be obtained based on the above equations.

\section{Numerical examples}

\subsection{The beam-cable structural system}

A simple beam-cable structural system is shown in Figure 1. The length of the beam is $2 l=12 \mathrm{~m}$, the length of cables is $L=3 \mathrm{~m}$. The cross section of the beam is a $b \times h$ rectangle. The cross sectional area of the cable is $A_{i}(i=1,2)$. The plastic limit bending moment of the beam is $M$. The yield limit stress of the cable and the beam are $\sigma_{1}$ and $\sigma_{2}$, respectively. $q$ is the uniformly distributed load. The random variables $(b, h$, $A_{1}, A_{2}, \sigma_{1}, \sigma_{2}$ and $q$ ) with known first four moments are assumed to be independent, and the probabilistic properties are listed in Table 2.

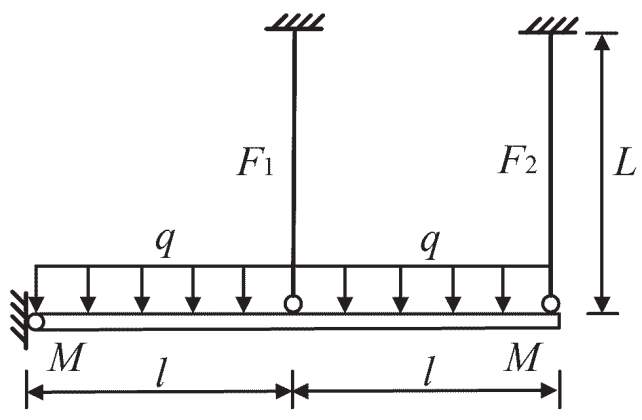

Fig. 1. Beam-cable structural system

There are four failure modes of the beam-cable structural system [23], the corresponding limit state functions are listed in Table 3. ( $M=W f_{y}, W=b h^{2} / 6$ is the section modulus of bending of the beam, with the coefficient $f_{y}=0.134$ ).

According to the PNET method, the failure modes with the correlation coefficients higher than $\rho_{0}=0.8$ are selected as the representative failure modes, which are $g_{2}$ and $g_{1}$. Then, the system failure probability of the beam-cable system could be expressed as the following form according to equation (20).

$$
\begin{aligned}
P & =P\left(g_{1}(\boldsymbol{X}) \leq 0\right)+P\left(g_{2}(\boldsymbol{X}) \leq 0\right)-P\left(g_{1}(\boldsymbol{X}) \leq 0 \cap g_{2}(\boldsymbol{X}) \leq 0\right) \\
& =P_{1}+P_{2}-C\left(P_{1}, P_{2}\right)
\end{aligned}
$$


Table 2. The first four moments of random variables

\begin{tabular}{lllll}
\hline \hline Random variables & Mean & Standard deviation & The third moment & The fourth moment \\
\hline$b(\mathrm{~mm})$ & 152 & 0.76 & $1.4223 \mathrm{e}-1$ & 1.1723 \\
$h(\mathrm{~mm})$ & 200 & 1 & $3.2400 \mathrm{e}-1$ & 3.5140 \\
$A_{1}\left(\mathrm{~cm}^{2}\right)$ & 6.45 & 0.032 & $1.0617 \mathrm{e}-5$ & $3.6847 \mathrm{e}-6$ \\
$A_{2}\left(\mathrm{~cm}^{2}\right)$ & 3.32 & 0.017 & $1.5918 \mathrm{e}-6$ & $2.9349 \mathrm{e}-7$ \\
$\sigma_{1}(\mathrm{MPa})$ & 413.6 & 41.36 & $2.2924 \mathrm{e} 4$ & $1.0283 \mathrm{e} 7$ \\
$\sigma_{2}(\mathrm{MPa})$ & 300 & 30 & $8.7480 \mathrm{e} 3$ & $2.8463 \mathrm{e} 6$ \\
$q(\mathrm{kN} / \mathrm{m})$ & 29 & 5.84 & $6.4434 \mathrm{e} 1$ & $4.0791 \mathrm{e} 3$ \\
\hline \hline
\end{tabular}

According to the PNET method, the representative failure modes of the six-bar truss structural system is determined, which are $g_{15}$, $g_{1}$ and $g_{6}$. The failure probability of each failure modes could be obtained as,

$$
\begin{gathered}
P_{15}=0.0657, P_{1}=1.1102 \mathrm{e}-16, P_{6}=0 \\
C\left(P_{15}, P_{1}\right)=1.1102 \mathrm{e}-16, C\left(P_{15}, P_{6}\right)=0,
\end{gathered}
$$

$$
C\left(P_{1}, P_{6}\right)=0, C\left(P_{15}, P_{1}, P_{6}\right)=0
$$

Table 3. The limit state functions of the potential failure modes in example 5.1

\begin{tabular}{l|l}
\hline \hline$g_{1}=6 M-q l^{2} / 2$ & $g_{3}=M+A_{2} \sigma_{2} l-q l^{2} / 2$ \\
$g_{2}=A_{1} \sigma_{1} l+2 A_{2} \sigma_{2} l-2 q l^{2}$ & $g_{4}=2 M+A_{1} \sigma_{1} l-q l^{2}$ \\
\hline \hline
\end{tabular}

The failure probability of each failure mode and the joint failure probability could be calculated with equation (19-21) and equation (4), respectively:

$$
P_{1}=0.0057, P_{2}=0.0052, C\left(P_{1}, P_{2}\right)=3.5 \mathrm{e}-04
$$

Thereout, the system failure probability and system reliability could be obtained as:

$$
P=P_{1}+P_{2}-C\left(P_{1}, P_{2}\right)=0.0574, R=1-P=0.9426
$$

To validate the result, a Monte Carlo simulation is carried out with $10^{6}$ samples and gives $R_{\mathrm{MCS}}=0.9819$, the relative error is $\rho_{P}=\left|R-R_{\mathrm{MCS}}\right|$ $R_{\mathrm{MCS}}=4 \%$.

Based on the reliability analysis results, the reliability-based sensitivity could then be obtained according to equation (21).

$$
\frac{\partial P}{\partial \overline{\boldsymbol{X}}^{\mathrm{T}}}=\left[\begin{array}{l}
\partial P / \partial b \\
\partial P / \partial h \\
\partial P / \partial A_{1} \\
\partial P / \partial A_{2} \\
\partial P / \partial \sigma_{1} \\
\partial P / \partial \sigma_{2} \\
\partial P / \partial q
\end{array}\right]=\left[\begin{array}{l}
-6.0246 \mathrm{E}-4 \\
-9.1574 \mathrm{E}-4 \\
-5.3980 \mathrm{E} 2 \\
-7.8308 \mathrm{E} 2 \\
-8.4181 \mathrm{E}-10 \\
-8.6661 \mathrm{E}-10 \\
1.7685 \mathrm{E}-5
\end{array}\right] \quad \frac{\partial P}{\partial \operatorname{Var}(\boldsymbol{X})}=\left[\begin{array}{l}
\partial P / \partial \operatorname{Var}(b) \\
\partial P / \partial \operatorname{Var}(h) \\
\partial P / \partial \operatorname{Var}\left(A_{1}\right) \\
\partial P / \partial \operatorname{Var}\left(A_{2}\right) \\
\partial P / \partial \operatorname{Var}\left(\sigma_{1}\right) \\
\partial P / \partial \operatorname{Var}\left(\sigma_{2}\right) \\
\partial P / \partial \operatorname{Var}(q)
\end{array}\right]=\left[\begin{array}{l}
1.0203 \mathrm{E}-4 \\
2.3574 \mathrm{E}-4 \\
5.7931 \mathrm{E} 6 \\
1.2191 \mathrm{E} 7 \\
1.4089 \mathrm{E}-17 \\
1.4931 \mathrm{E}-17 \\
6.0273 \mathrm{E}-9
\end{array}\right]
$$

The results display that the failure probability of the beam-cable structural system descends as the dimension parameter $b, h, A_{i}$ and yield stress $\sigma_{i}$ increase, but increases as the load $q$ rises. Among all the random variables considered, the failure probability has a high dependency on $A_{i}$.

\subsection{The six-bar truss structural system}

As shown in Figure 2 is a six-bar truss structural system with five applied concentrated load $F_{i}(i=1,2, \ldots, 5)$. All the bars are made of the same material with the yield limit $\sigma$. The cross section of each bar is $A_{i}(i=1,2, \ldots, 6)$. The limit state functions of the potential failure modes of the structural system are listed in Table 4 [3]. The random variables $\left(A_{i}, F_{i}\right.$, and $\left.\sigma\right)$ are independent with each other, and the probabilistic properties with known first four moments are listed in Table 5.

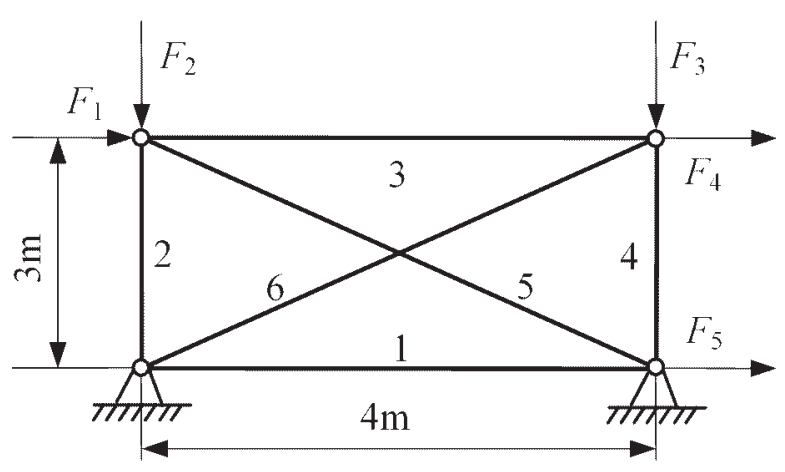

Fig. 2. Six-bar truss structural system

Table 4. The limit state functions of the potential failure modes in example 5.2

\begin{tabular}{l|l}
\hline \hline $\mathrm{g}_{1}=3 \mathrm{~A}_{1} \sigma+4 \mathrm{~A}_{2} \sigma-4 \mathrm{~F}_{2}-3 \mathrm{~F}_{5}$ & $\mathrm{~g}_{9}=20 \mathrm{~A}_{2} \sigma+12 \mathrm{~A}_{6} \sigma-15 \mathrm{~F}_{1}+20 \mathrm{~F}_{2}-15 \mathrm{~F}_{4}$ \\
$\mathrm{~g}_{2}=\mathrm{A}_{1} \sigma+\mathrm{A}_{3} \sigma-\mathrm{F}_{1}-\mathrm{F}_{5}$ & $\mathrm{~g}_{10}=3 \mathrm{~A}_{3} \sigma+4 \mathrm{~A}_{4} \sigma-4 \mathrm{~F}_{3}-3 \mathrm{~F}_{4}$ \\
$\mathrm{~g}_{3}=3 \mathrm{~A}_{1} \sigma+4 \mathrm{~A}_{4} \sigma-3 \mathrm{~F}_{1}-4 \mathrm{~F}_{3}-3 \mathrm{~F}_{5}$ & $\mathrm{~g}_{11}=5 \mathrm{~A}_{3} \sigma+4 \mathrm{~A}_{5} \sigma-5 \mathrm{~F}_{1}$ \\
$\mathrm{~g}_{4}=5 \mathrm{~A}_{1} \sigma+4 \mathrm{~A}_{5} \sigma-5 \mathrm{~F}_{5}$ & $\mathrm{~g}_{12}=5 \mathrm{~A}_{3} \sigma+4 \mathrm{~A}_{6} \sigma-5 \mathrm{~F}_{4}$ \\
$\mathrm{~g}_{5}=5 \mathrm{~A}_{1} \sigma+4 \mathrm{~A}_{6} \sigma-4 \mathrm{~F}_{1}-4 \mathrm{~F}_{4}-4 \mathrm{~F}_{5}$ & $\mathrm{~g}_{13}=20 \mathrm{~A}_{4} \sigma+12 \mathrm{~A}_{5} \sigma-15 \mathrm{~F}_{1}-20 \mathrm{~F}_{3}-15 \mathrm{~F}_{4}$ \\
$\mathrm{~g}_{6}=4 \mathrm{~A}_{1} \sigma+3 \mathrm{~A}_{3} \sigma-3 \mathrm{~F}_{1}+4 \mathrm{~F}_{2}$ & $\mathrm{~g}_{14}=5 \mathrm{~A}_{4} \sigma+3 \mathrm{~A}_{6} \sigma-5 \mathrm{~F}_{3}$ \\
$\mathrm{~g}_{7}=4 \mathrm{~A}_{2} \sigma+4 \mathrm{~A}_{4} \sigma-3 \mathrm{~F}_{1}+4 \mathrm{~F}_{2}-4 \mathrm{~F}_{3}-3 \mathrm{~F}_{4}$ & $\mathrm{~g}_{15}=4 \mathrm{~A}_{5} \sigma+4 \mathrm{~A}_{6} \sigma-5 \mathrm{~F}_{1}-5 \mathrm{~F}_{4}$ \\
$\mathrm{~g}_{8}=5 \mathrm{~A}_{2} \sigma+3 \mathrm{~A}_{5} \sigma-5 \mathrm{~F}_{2}$ & \\
\hline
\end{tabular}

Thus, the system failure probability and the system reliability could be obtained as:

$P=P_{15}+P_{1}+P_{6}-C\left(P_{15}, P_{1}\right)-C\left(P_{15}, P_{6}\right)-C\left(P_{1}, P_{6}\right)+C\left(P_{15}, P_{1}, P_{6}\right)=0.0657$

$$
R=1-P=0.9343
$$

To validate the result, a Monte Carlo simulation is carried out with $10^{6}$ samples and gives $R_{\mathrm{MCS}}=0.9668$, compare the result with that of the proposed method, the relative error is $\varepsilon_{R}=\left|R-R_{\mathrm{MCS}}\right| / R_{\mathrm{MCS}}=3.36 \%$.

Based on the above results, the reliability-based sensitivity of the structural system could then be obtained according to equation (21). 
Table 5. Probabilistic properties of random variables

\begin{tabular}{lllll}
\hline \hline Random variables & Mean & Standard deviation & The third moment & The fourth moment \\
\hline$A_{1}\left(\mathrm{~mm}^{2}\right)$ & 250 & 1.25 & $6.3281 \mathrm{e}-1$ & 8.5791 \\
$A_{2}\left(\mathrm{~mm}^{2}\right)$ & 100 & 0.5 & $4.0500 \mathrm{e}-2$ & $2.1963 \mathrm{e}-1$ \\
$A_{3}\left(\mathrm{~mm}^{2}\right)$ & 100 & 0.5 & $4.0500 \mathrm{e}-2$ & $2.1963 \mathrm{e}-1$ \\
$A_{4}\left(\mathrm{~mm}^{2}\right)$ & 250 & 1.25 & $6.3281 \mathrm{e}-1$ & 8.5791 \\
$A_{5}\left(\mathrm{~mm}^{2}\right)$ & 250 & 1.25 & $6.3281 \mathrm{e}-1$ & 8.5791 \\
$A_{6}\left(\mathrm{~mm}^{2}\right)$ & 150 & 0.75 & $1.3669 \mathrm{e}-1$ & 1.1119 \\
$F_{1}(\mathrm{kN})$ & 50 & 2.5 & 5.0625 & $1.3727 \mathrm{e} 2$ \\
$F_{2}(\mathrm{kN})$ & 30 & 1.5 & 1.0935 & $1.7790 \mathrm{e} 1$ \\
$F_{3}(\mathrm{kN})$ & 30 & 1.5 & 1.0935 & $1.7790 \mathrm{e} 1$ \\
$F_{4}(\mathrm{kN})$ & 20 & 1.0 & 0.324 & 3.514 \\
$F_{5}(\mathrm{kN})$ & 20 & 1.0 & 0.324 & 3.514 \\
$\sigma(\mathrm{MPa})$ & 240 & 12 & $5.5987 \mathrm{e} 2$ & $7.2866 \mathrm{e} 4$ \\
\hline \hline
\end{tabular}

\section{Conclusions}

This paper presents a system reliability and parameter sensitivity analysis method of structural systems with correlated failure modes. The reliability of the component failure is estimated with the perturbation theory and the moment method. The system reliability of the structural system is firstly simplified by adopting the probabilistic network evaluation technique, and then is analysed with consideration of the correlation between each component failure. The Archimedean copula function is served as the modelling tool to establish the copula-based joint distribution function. The parameter sensitivity analysis is realized by matrix differential technology. The results of the numerical examples serve as testimony to the effectiveness of the proposed method and should be useful when considering the reliability problem of structural systems with correlated failure modes.

\section{Acknowledgement}

The work is supported by National Natural Science Foundation of China (51405490), A Project Funded by the Priority Academic Program Development of Jiangsu Higher Education Institutions (PAPD) and the Fundamental Research Funds for the Central Universities (2013QNA23).

The results show that the failure probability of the six-bar truss structural system descends as the cross section of each bar $A_{i}$ and the yield stress $\sigma$ increase, but increases as the load $F_{i}$ rises. It is necessary to mention that the system reliability sensitivity with respect to the variables $A_{4}$ and $F_{3}$ are 0 because of the two variables are not involved in the representative failure modes. Besides, in terms of the degree of influences, the system reliability is very sensitive to cross section $A_{5}$, $A_{6}$ and yield limit $\sigma$.

\section{References}

1. Bichon B J, McFarland, J M, Mahadevan S. Efficient surrogate models for reliability analysis of systems with multiple failure modes. Reliability Engineering \& System Safety 2011; 96(10): 1386-1395, http://dx.doi.org/10.1016/j.ress.2011.05.008.

2. Bücher A, Dette H, Volgushev S. A test for Archimedeanity in bivariate copula models. Journal of Multivariate Analysis 2012; 110(9): 121132, http://dx.doi.org/10.1016/j.jmva.2012.01.026.

3. Cardoso J B, de Almeida J R, Dias J M, et al. Structural reliability analysis using Monte Carlo simulation and neural networks. Advances in Engineering Software 2008; 39(6): 505-513, http://dx.doi.org/10.1016/j.advengsoft.2007.03.015.

4. Corbella S, Stretch D D. Simulating a multivariate sea storm using Archimedean copulas. Coastal Engineering 2013:76(6): 68-78, http:// dx.doi.org/10.1016/j.coastaleng.2013.01.011.

5. Chang Y, Mori Y. A study on the relaxed linear programming bounds method for system reliability. Structural Safety 2013; 41(2): 64-72, http://dx.doi.org/10.1016/j.strusafe.2012.11.002.

6. Eryilmaz S. Estimation in coherent reliability systems through copulas. Reliability Engineering \& System Safety 2011; 96(5): 564-568, http://dx.doi.org/10.1016/j.ress.2010.12.024.

7. Hofert M. Sampling Archimedean copulas. Computational Statistics \& Data Analysis 2008; 52(12): 5163-5174, http://dx.doi.org/10.1016/j. csda.2008.05.019.

8. Hohenbichler M, Rackwitz R. First-order concepts in system reliability. Structural Safety 1983; 1(3):177-88, http://dx.doi.org/10.1016/01674730(82)90024-8.

9. Kang W H, Song J, Gardoni P. Matrix-based system reliability method and applications to bridge networks. Reliability Engineering \& System Safety 2008; 93(11):1584-1593, http://dx.doi.org/10.1016/j.ress.2008.02.011.

10. Katsuya M, Shinji N, Kazuhiro I, Masataka Y, Nozomu K. Reliability-based structural optimization of frame structures for multiple failure criteria using topology optimization techniques. Structural and Multidisciplinary Optimization 2006; 32(4): 299-311, http://dx.doi. org/10.1007/s00158-006-0039-5. 
11. Li C, Zhang Y, Wang Y. Gradual reliability and its sensitivity analysis approach of cutting tool in invariant machining condition and periodical compensation. Jixie Gongcheng Xuebao(Chinese Journal of Mechanical Engineering), 2012; 48(12): 162-168, http://dx.doi.org/10.3901/ JME.2012.12.162.

12. Lemaître P, Sergienko E, Arnaud A, et al. Density modification-based reliability sensitivity analysis[J]. Journal of Statistical Computation and Simulation, 2015; 85(6): 1200-1223, http://dx.doi.org/10.1080/00949655.2013.873039.

13. Lu H, He Y H, Zhang Y M. Reliability-Based robust design of Mechanical Components with Correlated Failure Modes Based on Moment Method. Advances in Mechanical Engineering 2014; 2014(6): 1-17.

14. Lu H, Zhang Y M. Reliability-Based Robust Design for Structural System with Multiple Failure Modes. Mechanics Based Design of Structures and Machines 2011; 39(4): 420-440 ,http://dx.doi.org/10.1080/15397734.2011.560541.

15. Ma H F, Ang A H S. Reliability Analysis of Redundant Ductile Structural Systems. Urbana Champaign: University of Illinois, 1981.

16. Naess A, Leira B J, Batsevychc O. System reliability analysis by enhanced Monte Carlo simulation. Structural Safety 2009; 31(5): 349-355, http://dx.doi.org/10.1016/j.strusafe.2009.02.004.

17. Nelsen R B. An introduction to copulas. Springer Verlag, 2006.

18. Pfeifer D, Nešlehová J. Modeling dependence in finance and insurance: the copula approach. Blätter der DGVFM, 2003; 26(2): 177-191, http://dx.doi.org/10.1007/BF02808371.

19. Song J H, Kiureghian A D. Bounds on system reliability by linear programming. Journal of Engineering Mechanics 2003; 129(6): 627-636, http://dx.doi.org/10.1061/(ASCE)0733-9399(2003)129:6(627).

20. Sklar A. Fonctions de répartition à n dimensions et leurs marges. Publications de l'Institut de Statistique de l'Université de Paris, 1959; 8: 229-231.

21. Sklar A. Random variables, joint distribution functions, and copulas. Kybernetika 1973; 9: 449-460.

22. Tang X S, Li D Q, Zhou C B, Phoon K K, Zhang L M. Impact of copulas for modeling bivariate distributions on system reliability. Structural Safety 2013; 44(9):80-90, http://dx.doi.org/10.1016/j.strusafe.2013.06.004.

23. Zhao Y G, Ang A H S. System reliability assessment by method of moments. Journal of Structural Engineering 2003; 129(10): 1341-1349, http://dx.doi.org/10.1061/(ASCE)0733-9445(2003)129:10(1341).

24. Zhang Y M, Yang Z. Reliability-based sensitivity analysis of vehicle components with non-normal distribution parameters. International Journal of Automotive Technology 2009; 10(2): 181-194, http://dx.doi.org/10.1007/s12239-009-0022-4.

25. Zhang F, Lu Z Z, Cui L J, Song S F. Reliability Sensitivity Algorithm Based on Stratified Importance Sampling Method for Multiple Failure Modes Systems. Chinese Journal of Aeronautics 2010; 23(6): 660-669, http://dx.doi.org/10.1016/S1000-9361(09)60268-5.

\section{Lu HAO} \\ College of Mechanical and Electrical Engineering \\ China University of Mining and Technology (Nanhu Campus), No.1 \\ Daxue Road, Xuzhou, China. Postcode: 221116 \\ Jiangsu Key Laboratory of Mine Mechanical and Electrical Equipment \\ China University of Mining \& Technology \\ Xuzhou, China. Postcode: 221116
}

\title{
Zhu ZHENCAI
}

College of Mechanical and Electrical Engineering

China University of Mining and Technology (Nanhu Campus), No.1

Daxue Road, Xuzhou, China. Postcode: 221116

E-mail: haolucumt@163.com; zhulscumt@163.com 